\title{
An Investigation of Intestinal Parasitic Infections Among the Asymptomatic Children in, Southern Ethiopia
}

\author{
Abayneh Unasho*
}

\author{
Biomedical Sciences, Dilla University, Ethopia
}

\begin{abstract}
Background: Children under five years, particularly aged 2-4 years (24-48 months), are more vulnerable to intestinal parasitic infections. This is because, children with this ages may contract infective agents during their intense activities, and adventures such as crawling or walking on bare ground, sand or grasses or eating mud/pica. Increased population density, lack of awareness, poor sanitation, and poor public health practices, and environmental sanitations, affect the prevalence of parasitic infection in tropical countries. Moreover, the prevalence of intestinal parasitic infections among the asymptomatic children aged under five is not well studied.
\end{abstract}

Objectives: The objectives of this study was to investigate the prevalence of intestinal parasitic infections among the asymptomatic children aged 6-59 months in selected Southern Ethiopia including Gedeo, Amaro, Walyta and Kambata.

Methods: A cross-sectional study was carried out and the sampling design combined multistage sampling methods including, both simple random sampling technique, population density and systematic random sampling techniques. The course of this study took over a period of 5 months, from September 2009 to January 2010. Study participants were estimated by convenient sampling method to include 406 asymptomatic children (217 females and 189 males) from the systematically selected households of the study sites. Parasitological diagnosis of the parasites was done using the standard parasite and ova method. A total of 406 stool specimens were examined by a direct microscopy using a normal saline $(0.9 \%)$ and lugol's iodine wet mount techniques to determine the infection of intestinal parasites and the analysis of the data was made manually using thematic framework method.

Results: Of the total 406 study participants, 170 (41.9\%) children were found to have single and double intestinal parasitic infections whilst $236(58 \%)$ children were free from the suspected parasites. Ascaris, lumbricoides, amoeba spp, Giardia lamblia, Trichuris trichiura, hookworms spp, Strongyloides stercoralis, and Hymenolepis nana were identified in both single and double infections. Double infections were found in 19 (11.2\%) asymptomatic children of the total positive cases and the rest were single infections. In both single and double infections, ascaris was found to be the most dominant infective agent accounted $111(59 \%)$ out of the total 187 parasitic load of infection, followed by amoeba spp.31 (16.6\%) and Trichuris trichiura 17(9\%). Higher proportions of infected age groups were 25-48 while the least infected age groups were 6-24 and 49-59 months.

Concluding Remarks and Recommendations: This baseline study indicated higher prevalence of intestinal parasitic infections in the study area and therefore, much effort is remaining to fight against parasitic infection. Along with regular deworming intervention, health education including infection cycle, environmental sanitation, personal hygiene, use of potable water and proper use of latrine should be given due attention to prevent and control parasitic infections among children in both urban and rural areas.

Keywords: Infection, parasitosis, Prevalence, Diagnosis, Specimen, Sanitation.

\section{INTRODUCTION}

Even though treatment, prevention, and control measures are available, parasitic infections still occur worldwide. However, most parasitic infections are found in underdeveloped, tropical and subtropical countries. Increased population density, poor sanitation, and poor public health practices, inadequate toilet facilities, contaminated food and water, under nutrition, lowering resistance of the host, and environmental changes can affect the prevalence of parasitic infection [1-3].

Children aged 2-4 years (24-48 months), are more vulnerable to infection because children less than 4 years old may contract infections during intense

*Address correspondence to this author at the Biomedical Sciences, Dilla University, Ethopia; Tel: +251911895949;

E-mail: aabbay_u@yahoo.com activities and adventures such as crawling or walking on bare ground, sand or grasses. Transmission of parasitic infection can also occur during outdoor play using no shoes on soil contamination with feces [4]. Another study result conducted in Karachi on the frequency of risk factors for parasitic infection in children under five years also shows that out of 269 children, $36 \%$ of the children were eating mud/pica and were positive for soil transmitted intestinal parasites [5], indicating soil contamination is one of the sources of infection.

Intestinal parasitic infections caused by protozoa and helminthes are global endemic constituting the greatest cause of illness and disease, and infect more than two billion people worldwide [6]. Giardia lamblia (intestinalis), causing giardiasis is the most prevalent protozoan parasite worldwide with about 200 million people being infected currently [7]. Ascaris 
lumbricoides, Trichuris trichiura, Strongyloides stercoralis and hookworms are collectively called soil transmitted helminthes and are the most common intestinal parasites [8]. It is estimated that globally, $A$. lumbricoides infects 1.22 billion people, T. trichura 795 million and hookworms 740 million people [9] indicating wide distribution of these parasites. Moreover, several studies worldwide also show that the prevalence of $A$. lumbricoides and $T$. trichura is very high in patients examined, when compared with other intestinal parasites such as hookworms, Stronyloides stercoralis, Hymenolepis nana and others [10].

Parasitic infection causing diseases deprive the poorest of the poor health, contributing to economic instability, and social marginalization, and the poor people of underdeveloped nations experience a cycle where undernutrition and repeated infections lead to excess morbidity that can continue from generation to generation [11]. Parasites also exacerbate the protein, caloric, and vitamin deficiencies and cause malnutrition [12]. Children, particularly, those who are under the age of 5 years may have severe nutritional impairment related to the worm burden (load). Directly measurable effects include increased nitrogen and fecal fat, and impaired carbohydrate absorption. Physical fitness, cognitive performance, and school attendance of school aged children can be affected by parasitic infections [13, 14]. Therefore, in order to avoid/reduce malnutrition and guarantee healthy growth of children, we should feed kids, but not worms.

In Ethiopia, intestinal parasitic infection has been widespread and causes serious public health problem. They are more prevalent in the poor segments of the population with low household income, poor handling of personal and environmental sanitation, overcrowding and limited access to clean water [15]. Many reports illustrate that $A$. lumbricoides is the most prevalent intestinal parasite in different communities of Ethiopia, usually occurring together with Trichuris trichiura infection. Hookworms, Strongyloides stercoralis and enterobiasis infection are also public health problem, though; the magnitude is less compared to ascariasis [16] indicating the need to intervene in fighting against the infection of intestinal parasites.

The aim of this study was to generate baseline information on intestinal parasitic infection among the asymptomatic children under five years (=healthy carriers) in selected Southern regions of Ethiopia so that the result may have a value to supplement millennium development goal and health strategy of Ministry of Health.

\section{MATERIALS AND METHODS}

\subsection{Description of the Study Area}

\section{Southern Ethiopia}

Southern Nations, Nationalities' and Peoples' Regional State (SNNPRS) is one of the nine regional states of Ethiopia. Total Population of Southern region has an estimated population over 15 million. Close to $90 \%$ of the population is estimated to be rural inhabitants like all other regions in the country. With an estimated area of $112,343.19$ square kilometers, this region has an estimated density of 132.65 people per square kilometer making this region, one of the most densely populated in the country, with 56 ethnic groups; and have poor health conditions [17].

In a less developed countries, including Ethiopia, studies showed, children, particularly those who are under the age of 5 years may have severe nutritional impairment related to different factors including parasitic infection which needs rapid and integrated interventions.

\subsection{Study Design}

A cross-sectional study was carried out and the sampling design combined a multistage sampling technique including simple random sampling, population density and systematic random sampling method. The study was conducted at southern Ethiopia including selected kebeles of Gedeo, Wolyta and Kambata zones and Amaro special woreda. After a pilot study on one of the selected kebeles (Peasant associations), data collection was conducted from Sept 2009 to January 2010 over a period of 5 months.

Simple random sampling techniques were used to select Zones, and study sites (kebeles), while Woreda, administrations were selected based on population density to have a total of eight study sites having expected households. Using conventional method, a total of sixty households were considered from each study site, and using systematic random sampling method, households from which study participants could be recuireted were selected.

Recruitment of the asymptomatic children from each household was done by trained kebele extension workers who used, check lists, and admission slips, 
during the time of sampling. Most of the investigation of the intestinal parasites, all data analysis and interpretations were done by the investigator.

\subsubsection{Study Participants and Techniques of Sampling}

From a selected household, only one child was included in the study group, but in case whenever, there were two children or twins in a target group, a lottery system was used to select one child from each selected household. However, children who were visitors or stayed less than a month, or children who were on anti- parasitic drug or children coming to clinics for treatment/ at the time of sampling, were intentionally excluded from the data collection to maintain the study design. Moreover, whenever, a household was lacking targeted child, the next household was considered. The selected households including children were registered, considering the name of a child, age, sex, educational background of the family, kebele, household code, etc in the check list, and admission card was given to mothers /care takers to bring it to selected field laboratory for further interview and stool examination. Sample collection was not only restricted to families living in easily accessible households such as those that are close to main roads, but also included households that were hard to reach areas.

Sample size was estimated by convenient sampling method assuming 60 children from each sampling unit ( 8 study sites $\times 60=480$ children) because with the limited resource allocation, conducting true representative probability sampling was not adequate.

\subsection{Diagnosis of Parasites: Stool Collection and Processing}

When this study was carried out, the overall study participants were 464 asymptomatic children under five years. After completing, a short questionnaire that included age of children, sex, as well as members of the family, level of parental education and environmental and personal hygiene/sanitation, mothers/caretakers were given a cup with lid containing a few drops of physiological saline for the collection of small quantity of stool specimen. Standard parasitological technique was selected and stool examination for intestinal parasites was conducted.

The double normal physiological saline wet mount smear (direct microscopy) was employed for the stool examination in order to minimize the error of false negatives. Moreover, wet mount smear was so thin enough that news paper print can be read through the smear of a slide, which is the best smear for fecal examination [18]. Weak iodine wet mount was also used to observe nuclear characteristics of cysts and trophozoites identification. The smear was then examined under the microscope (100X, 400X) (Figure 1).

\subsubsection{Data Analysis}

Descriptive statistics using Tables and proportions were used to give a clear picture of background characteristics such as age, sex, infection rate and distribution of the parasites among children and data analysis of the result was done manually using both

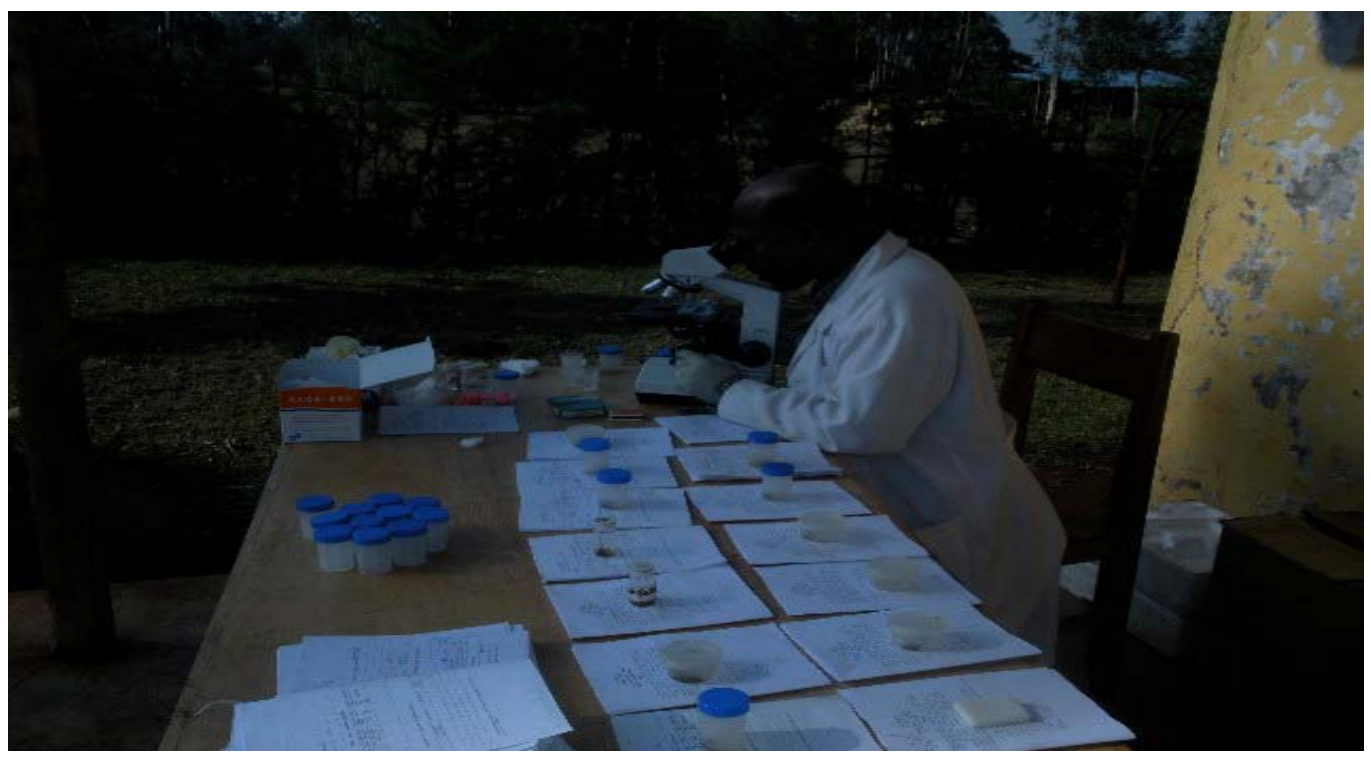

Figure 1: Diagnosis of intestinal parasites at the field laboratory. 

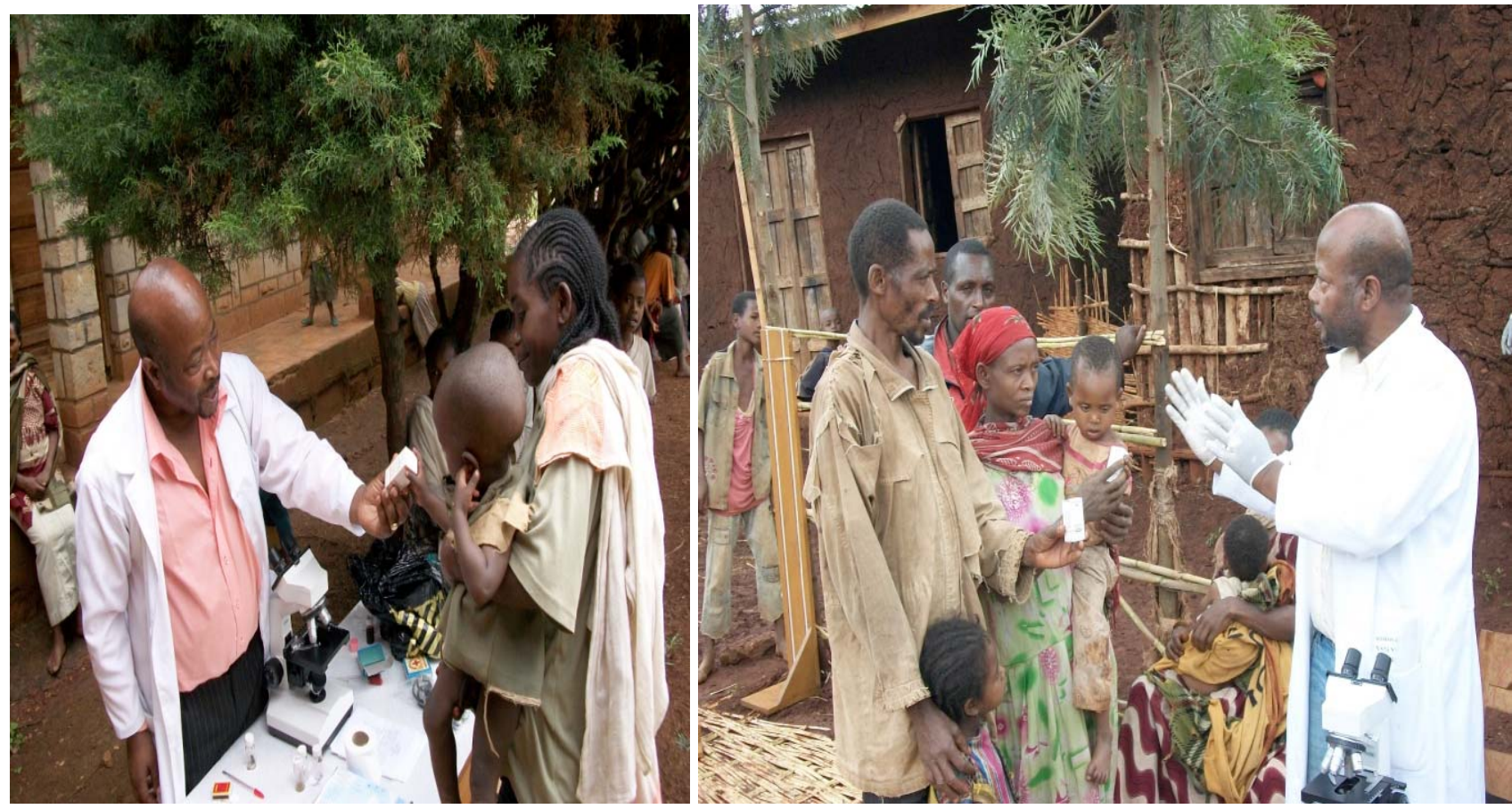

Figure 2: provision of anti parasitic drug and process of counseling (= we should feed kids, but not worms!!!)

quantitative and qualitative research parameters involving thematic framework method.

\subsubsection{Ethical Clearance}

Prior to research conduction, written permission regarding ethical approval was obtained from the Southern Regional Health Office and Dilla University Research and Dissemination Office (RDO). Moreover, verbal consent was also obtained from each household mother /care takers of children before recruiting, and examination of intestinal parasites. Besides, explanation was given about the procedure of stool examination that it is non invasive and have no harm to the study participants and the aim of the study result may benefit the study participants and community as well. All the asymptomatic children, who were positive for any of the suspected intestinal parasites, were given antiparastic drugs as per the prescription of the pediatrician (Figure 2) and mothers were told to report if they encounter any side effects.

\section{RESULTS AND DISCUSSIONS}

\subsection{Results}

A total of 464 study participants were selected for the diagnosis of intestinal parasites, from which 58

Table 1: Frequency Distribution of Asymptomatic Children by Sex and Age

\begin{tabular}{|c|c|c|c|}
\hline Background characteristics & & Frequency & Percentage (\%) \\
\hline \hline \multirow{3}{*}{ 1. Gender } & Male & 189 & 46.6 \\
\cline { 2 - 4 } & Female & 217 & 53.4 \\
\cline { 2 - 4 } & Total & 406 & 100 \\
\hline \multirow{4}{*}{ 2. Age group (in months) } & $6-12$ & 72 & 17.7 \\
\cline { 2 - 4 } & $13-24$ & 95 & 23.4 \\
\cline { 2 - 4 } & $25-36$ & 112 & 27.6 \\
\cline { 2 - 4 } & $37-48$ & 102 & 25.1 \\
\cline { 2 - 4 } & $49-59$ & 25 & 6.2 \\
\cline { 2 - 4 } & Total & 406 & 100 \\
\hline
\end{tabular}


Table 2: Parasitic Infection Among the Asymptomatic Children Aged 6-59 Months

\begin{tabular}{|c|c|c|c|c|c|c|}
\hline \multirow{2}{*}{ № } & \multirow{2}{*}{$\begin{array}{c}\text { Regions (zones \& special } \\
\text { woreda) }\end{array}$} & \multirow{2}{*}{$\begin{array}{l}\text { Noo of children } \\
\text { examined }(n=406)\end{array}$} & \multicolumn{4}{|c|}{ № of children with } \\
\hline & & & positive cases & $\%$ & negative cases & $\%$ \\
\hline 1 & Gedeo & 117 & 63 & 53.8 & 54 & 46.2 \\
\hline 2 & Wolayta & 89 & 28 & 31.5 & 61 & 68.5 \\
\hline 3 & Kambata & 99 & 48 & 48.5 & 51 & 51.5 \\
\hline 4 & Amaro & 101 & 31 & 30.7 & 70 & 69.3 \\
\hline 5 & Total & 406 & 170 & 41.9 & 236 & 58.1 \\
\hline
\end{tabular}

(12.5\%) were intentionally excluded due to inability to provide stool specimens or unavailing themselves for the study. For this reason, a total of 406 study participants were included in the study, of which 170 $(41.9 \%)$ of the children were found to have single or double intestinal parasitic infections whilst 236 (58\%) children were free from the suspected intestinal parasites.

Moreover, of the total study participants under investigation (406), 217 (53.4\%) were females and 189 $(46.6 \%)$ were male children, (Table 1 ).

The ages of the study participants ranged from 6 months to 59 months (Table 1). Of the total participants, $72(17.7 \%)$ were in age group 6-12 months, whilst 95 (23.4\%), 112 (27.6\%), 102 (25.1\%), and $25(6.2 \%)$ were in 13-24, 25-36, 37-48 and 49-59 age groups respectively.

Besides, the infection rate and magnitude of intestinal parasites showed variation, in different study regions (Table 2). Of the total study participants (406),
(Table 2), 117 (28.8\%) were from the Gedeo zone, while 89 (21.9\%), 99 (24.4\%), and 101 (25.1\%) children were from Wolayta, Kambata, zones and Amaro special woreda respectively. The number of children participated in the study, varied in different zones and special woreda due to the fact that some recruited children were not able to provide stool for examination and some selected care takers/ mothers were not voluntary to bring their children to the examination center.

In Table 2, number of children with all, positive cases in different study regions also showed variations. Accordingly, in Gedo zone, out of 117 study participants, $63(53.8 \%)$ were positive cases followed by 48 (48.5\%) in Kambata, 31 (30.7\%), in Amaro special zone, and $28(31.5 \%)$ in Wolayta. Overall infection rate was 170 (41.9\%), of which Gedeo 63 (37\%) and Kambata 48 (28.2\%) zones took the lion's share of children infection while sampled children from Amaro, $31(18.8 \%)$ and Wolyta $28(16.5 \%)$ showed lower prevalence of intestinal parasitic infection.

Table 3: Infection and Types of Intestinal Parasites Among the Asymptomatic Children $(n=170)$

\begin{tabular}{|c|c|c|c|}
\hline No & Type of parasites & Frequency & \% \\
\hline \hline 1 & Protozoan parasites & & 16 \\
& Amoebic cysts & 30 & 0.5 \\
& Amoeba trophozoite & 1 & 2.7 \\
& Giardia cysts & 5 & 3.2 \\
\hline 2 & Giardia trophozorites & 6 & 59.4 \\
& Helminths-Nermatodes & 111 & 9.1 \\
\hline 3 & Ascaris lumbricoides & 17 & 2.7 \\
\hline & Trichuris trichiura & 5 & 2.7 \\
\hline & Hook worm spp & 5 & 100 \\
\hline
\end{tabular}


Different types of intestinal parasites included protozoan and helminthes (Cestodes and Nematodes) (Tables 3, 4) were detected from the stool samples of the study participants. The study results showed cysts, and trophozoites of protozoan parasites, eggs and larva of nematodes and cestode, parasites involving, both single and double infections.

Of the total 170 positive cases, 151 (88.8\%) of the children had single infection and 19 (11.2\%) children with double infection (Table 4). Common infection was due to Ascaris lumbricoides followed by amoeba species, and Trichuris trichiura. Of the total 170 infected cases, ascariasis, amoebiasis and trichuriasis predominated and accounted for 95 (55.9\%), 28 $(16.5 \%)$, and $8(4.7 \%)$ respectively as single infection, while the involvement of double infection indicated, Ascaris lumbricoides with Trichuris trichiura, 9 (5.3\%), Ascaris lumbricoides with Strongyloides stercoralis, 1 (0.59\%), Ascaris with hookworm spp, 2 (1.2\%), Ascaris lumbricoides with amoebic spp, 2 (1.2\%) and Ascaris lumbricoides with Giardia lamblia trophozoite 1 $(0.59 \%)$. Moreover, other double infections included hookworm spp with Hymenolopis nana accounts 1 $(0.59 \%)$, amoebic cyst with Giardia lamblia cyst 1 $(0.59 \%)$, Hymenolopis nana with amoebic cyst, 1 $(0.59 \%)$. were observed during the investigation.

In Table 5, of the total infected children, parasitic load of infections accounted a total of 187 (both single \& double infections) individual parasites. When the magnitude/load of of individual parasitic infection was considered, Ascaris lumbricoides was 111 (59.4\%) followed by amoeba species, being 31 (16.6\%) and Trichuris trichiura being 17 (9\%) as common infections.

Of the total parasitic load of infection, (187), Ascaris lumbricoides was found predominant parasite, found in all age groups, and showed the prevalence of $9(4.8 \%)$ in age group 6-12, 19 (10.2\%), in age group 13-24, 30 (16.1\%), in age group 25-36, $42(22.5 \%)$ in age 37-48, and $11(5.9 \%)$ in age group 49-59, while hookworm spp, $H$. nana, Strongylodes were found less frequent, and even some of them were absent in some age groups. However, Trichuris trichiura and amoeba species were more prevalent than these parasites as

Table 4: Magnitude (Load) of Individual Parasitic Infection in Asymptomatic Children $(n=170)$

\begin{tabular}{|c|c|c|c|c|}
\hline $\begin{array}{l}\text { Magnitude of } \\
\text { infection }\end{array}$ & Protozoan \& Helminthes parasites & $\begin{array}{l}\text { Frequency of infection in } \\
\text { examined children }\end{array}$ & Percent (\%) & REM \\
\hline \multirow{10}{*}{$\begin{array}{l}\text { 1.Single } \\
\text { infection }\end{array}$} & Ascaris lumbricoides & 95 & 55.9 & \\
\hline & Trichuris trichura & 8 & 4.7 & \\
\hline & Strongyloides stercoralis & 4 & 2.4 & \\
\hline & Hymenolopis nana & 4 & 2.4 & \\
\hline & Hook worm spp. & 2 & 1.2 & \\
\hline & Giardia trophozoite & 5 & 2.9 & \\
\hline & Giardia cyst & 4 & 2.4 & \\
\hline & Amoebic cyst & 27 & 15.9 & \\
\hline & Amoebic trophozoite & 1 & 0.59 & \\
\hline & Total number of children with single infections & 151 & 88.8 & \\
\hline \multirow{11}{*}{$\begin{array}{l}\text { 2.Double } \\
\text { infection }\end{array}$} & Ascaris lumbricoides \& T. trichiura & 9 & 5.3 & \\
\hline & Ascaris lumbricoides \& Strongyloides & 1 & 0.59 & \\
\hline & Ascaris lumbricoides \& Hookworm spp. & 2 & 1.2 & \\
\hline & Ascaris lumbricoides \& H. nana & 1 & 0.59 & \\
\hline & A. lumbricoides \& Amoebic cyst & 2 & 1.2 & \\
\hline & Hookworm \& H.nana & 1 & 0.59 & \\
\hline & Giardia trop \& A. lumbricoides & 1 & 0.59 & \\
\hline & Amoebic cyst \& Giardia cyst & 1 & 0.59 & \\
\hline & H. nana \& Amoebic cyst & 1 & 0.59 & \\
\hline & Total number children with double infections & 19 & 11.2 & \\
\hline & Total number of children infected & 170 & 100 & \\
\hline
\end{tabular}


Table 5: Types and Magnitude (Load) of Individual Parasitic Infection by Age and Sex of Infected Children

\begin{tabular}{|c|c|c|c|c|c|c|c|c|c|c|}
\hline \multicolumn{3}{|c|}{$\begin{array}{l}\text { Variables including } \\
\text { age and sex }\end{array}$} & \multirow{2}{*}{$\begin{array}{c}\text { G. } \\
\text { lamblia } \\
\text { No (\%) } \\
2(1.06)\end{array}$} & \multirow{2}{*}{$\begin{array}{c}\text { amoeba } \\
\text { spp } \\
\text { No (\%) } \\
5(2.7)\end{array}$} & \multirow{2}{*}{$\begin{array}{c}\text { A.lumbricoides } \\
\text { No (\%) } \\
9(4.8)\end{array}$} & \multirow{2}{*}{$\begin{array}{c}T . \\
\text { trichiura } \\
\text { No (\%) } \\
0(0.0)\end{array}$} & \multirow{2}{*}{$\begin{array}{c}\text { Hook } \\
\text { worm } \\
\text { SPP } \\
\text { No (\%) } \\
0(0.0)\end{array}$} & \multirow{2}{*}{$\begin{array}{c}\text { S. } \\
\text { stercoralis } \\
\text { No (\%) } \\
1(.5)\end{array}$} & \multirow{2}{*}{$\begin{array}{c}\text { H. nana } \\
\text { No (\%) } \\
0(0.0)\end{array}$} & \multirow{2}{*}{ 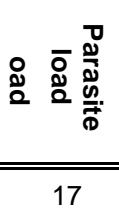 } \\
\hline 1 & Age & $6-12(n=15)$ & & & & & & & & \\
\hline & (months) & $13-24(n=32)$ & $2(1.06)$ & $5(2.7)$ & 19 (10.2) & $6(3.2)$ & $0(0.0)$ & $3(1.6)$ & $0(0.0)$ & 35 \\
\hline & & $25=36(n-56)$ & $4(2.1)$ & $16(8.6)$ & $30(16.1)$ & $4(2.1)$ & $\begin{array}{c}2 \\
(1.06)\end{array}$ & $1(.5)$ & $4(2.1)$ & 61 \\
\hline & & $37-48(n-55)$ & $3(1.6)$ & $5(2.7)$ & $42(22.5)$ & $6(3.2)$ & $1(.5)$ & $0(0.0)$ & $2(1.06)$ & 59 \\
\hline & & $49-59(n=12)$ & $0(0.0)$ & $0(0.0)$ & $11(5.9)$ & $1(.5)$ & $\begin{array}{c}2 \\
(1.06)\end{array}$ & $0(0.0)$ & $1(0.5)$ & 15 \\
\hline & & Total $=170$ & $\begin{array}{c}11 \\
(5.9 \%\end{array}$ & $\begin{array}{c}31 \\
(16.6 \%)\end{array}$ & $\begin{array}{c}111 \\
(59.4 \%)\end{array}$ & $\begin{array}{c}17 \\
(9 \%)\end{array}$ & $\begin{array}{c}5 \\
(2.7)\end{array}$ & $\begin{array}{c}5 \\
(2.7)\end{array}$ & $\begin{array}{c}7 \\
(3.7 \%)\end{array}$ & $\begin{array}{c}187 \\
(100 \%)\end{array}$ \\
\hline \multirow[t]{3}{*}{2} & \multirow[t]{3}{*}{ Sex } & Male $(n-80)$ & $5(2.7)$ & $15(8)$ & $55(29.4)$ & $12(6.4)$ & $3(1.6)$ & $2(1.06)$ & $2(1.06)$ & 94 \\
\hline & & $\begin{array}{c}\text { Female } \\
(\mathrm{n}=90)\end{array}$ & $6(3.2$ & $16(8.6)$ & $56(29.9)$ & $5(2.7)$ & $2(1.06)$ & $3(3.3)$ & $5(5.6)$ & 93 \\
\hline & & Total $=170$ & 11 & 31 & 111 & 17 & 5 & 5 & 7 & 187 \\
\hline
\end{tabular}

Burden of Parasitic infection in asymptomatic children

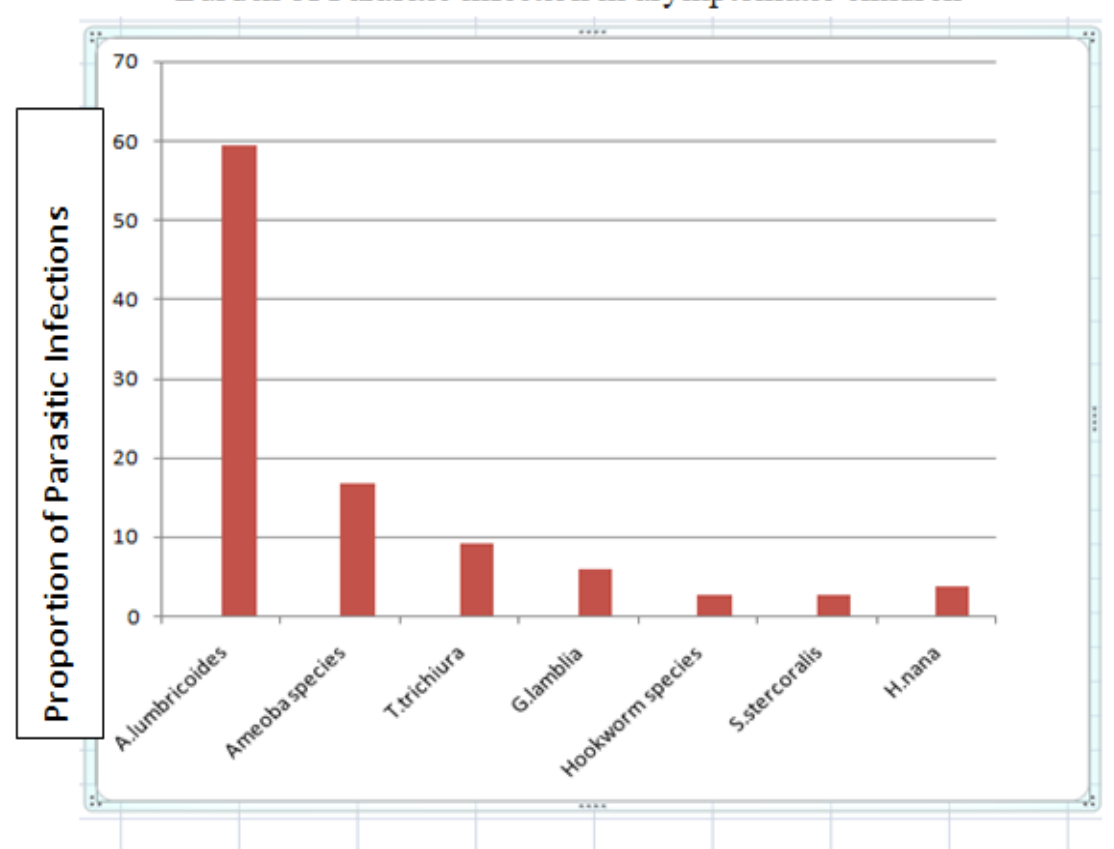

Figure 3: Types of parasites in both single and double infections.

shown in Table 5 . This study also showed that the most dominantly infected age groups were 25-48 month, whilst less infected age groups were 6-12, and 49-59 months old children.

Stool examination also showed infection of protozoan, parasites, including Giardia lamblia and amoeba species, nearly in all age groups of children, showing how risky is the epidemiology of the intestinal parasites among the children.

Much of the infections of the intestinal parasites did not show much variation on male and female children. However, infection of Trichuris trichiura was found more in male children (6.4\%) than females (2.7\%) (Table 5, Figure 3). 


\subsection{Discussion}

The study results indicated, of the total 406 study participants, $170(41.9 \%)$ of the asymptomatic children were infected with one or more intestinal parasites. Similar study on intestinal parasitic infection among preschool children in Thailand and Gaza (Palestine) shows lower prevalence of infection rating $22.2 \%$ [19] and $16.6 \%$ [25] respectively than this result (41.9\%). However, another similar survey on ecological determinants of the intestinal parasites among preschool children below five years in Urban settlement of Egypt also shows the overall prevalence of infection rates with helminthes and protozoa as $47.3 \%$ and $31.5 \%$ respectively which are relatively higher in the case of protozoan parasites and lower in the case of helminthes compared to this study results which indicated $71.4 \%$ of the helminthes and $28.6 \%$ of the protozoan infection. Moreover, the prevalence of helminthic parasites in this case was higher $(74.4 \%)$, compared to the study result on soil transmitted intestinal nematode parasitic infection of children in rural Guinea (Africa) which shows $53 \%$ of the children were infected by soil transmitted parasites of helminthes [24].

Despite of health intervention coverage of Ethiopian by the Ministry of Health, this finding showed a higher infection rate among children less than five years, which needs holistic and integrated efforts to control intestinal parasites.

Study results, also showed, that parasitic infection among children selected from each region showed variations, i.e. of the total children selected from Gedeo, Kambata, Wolyta zones and Amaro special woreda, infection variations was observed in each study site, showing $53.8 \%, 48.5 \%, 31.5 \%$ and $30.7 \%$ positive cases respectively (Table 2). Moreover, out of the total 170 infected cases in Gedeo, Kambata, Amaro and Wolyta, there were $37.1 \%, 28.2 \%, 18.2 \%$ and $16.5 \%$ infection cases respectively showing variation in zones and special woreda. It is very difficult to compare fully the overall infection rate of this parasitic infection with other studies, because most of the studies from other parts of Ethiopia were done on either school age children or at general population level [20].

However, this regional variation of intestinal parasitic infection may be due to differences in sample size, environmental and personal hygiene (poor sanitation), poverty related factors, poor public health practices, causing contamination of food and water [1, 3 , 15]. Another study results in Karachi and rural Guinea in Africa also show lack of hand washing, drinking unpurified water along with habit of eating mud/pica, could be the major contributing factors for the infection of the intestinal parasites in children under five years, [5, 24]. Study also show geophagia is an important risk factor for orally acquired nematode parasite (Ascaris and Trichuris) in children aged 1-5 years in Guinea, and recommends education regarding geophagia prevention is an integral component of any soil transmitted parasites [24].

Microscopic studies, showed different types of intestinal parasites including protozoa, and helminthes from the stool sample of study participants. When the total magnitude/load of individual parasitic infection was considered, Ascaris lumbricoides was $59.4 \%$ followed by amoeba species, being $16.6 \%$ and Trichuris trichiura being $9 \%$ as common infections. Another similar study was carried out on the asymptomatic children under five in southwest Ethiopia result shows the prevalence rate of Ascais lumbricoides and Trichuris trichura, being $31 \%$ and $30 \%$, respectively [20], showing variation of infection which may be due to the involvement of different factor in the transmission of parasites.

In line with this result, studies have also shown that Ascaris lumbricoides, Trichuris trichiura and hookworm spp are collectively soil transmitted helminthes and are the common intestinal parasites [8]. Moreover, the wide distribution of these parasites including amoeba species may be related to open field defecation of the people, poor hygienic condition of children, food and water contamination, humid and wet environment for the completion of the life cycle of the parasite and transmission [19]. Other parasites such as Hymenolopis nana (3.7\%), Strongyloides stercoralis (2.7\%) hookworm species, $(2.7 \%$ and Giardia lamblia $(5.9 \%)$ showed low prevalence rate among children, due to their specific factors, which needs further studies.

Studies have also shown that positive fecal samples often involve more than one pathogens [21], and in line with this result, my study also showed double infections. Accordingly, 19(11.2\%) children out of 170 positive cases had double infections mainly by ascaris and trichuris. The prevalence of double infection agreed with similar studies done in Southwest Ethiopia 
[19]. and slightly higher than similar studies conducted in Karachi-Pakistan which was 10\% [11]. Other double infections included Ascaris lumbricoides with Strongyloides, hookworm spp, Hymenolopis nana, Giardia trophozoite and amoebic cyst, Hookworm with Hymenolopis nana, amoebic cyst with Giardia lamblia and Hymeholopis nana with amoebic cyst (Table 4) showing how widely the parasites were distributed among the infected cases of children.

From this investigation and other studies, it is clear that high degree of multiple infections could have health hazards and related effects in children, like malnutrition, stunted and delayed growth, development, and poor educational achievement [22, 23]. Therefore, health aspect in general and pediatrics in particular need immediate interventions targeting prevention and control activities.

In this study, types and prevalence of individual parasitic infection by age and sex of the infected children was also determined (Table 5). Accordingly, among the intestinal parasites, ascaris was the most dominant parasite found in all age groups and showed the prevalence rate of $4.8 \%, 10.2 \%, 16.1 \%, 22.5 \%$, and $5.9 \%$ in age groups, $6-12,13-24,25-36,37-48$ and 49-59 respectively indicating, the highest prevalence rate of the parasitic infection, probably due to adaptation to the widest geographical and climatic conditions being common for intestinal parasites [8]. The low prevalence rate of Ascaris lumbricoides in age group 6-12 months old children in this study (4.8\%) agreed well with studies undertaken in preschool children in Rio de Jeneiro (4.3\%) [27] and Nigeria (7.6\%) [26].

Moreover, hookworm spp, $H$. nana, strongyloides were found less frequent and even in some cases / age groups, some of them were absent. Amoebic species and Trichuris trichura showed higher prevalence rates next to Ascaris lumbricoides while the prevalence of Giardia lamblia is lower than the two parasites, which may be due to specific adaptation of the parasites in a given environment.

The most dominantly infected age groups of children in this study were $25-48$ months old. This result agreed, with other study result which indicates, children aged 2-4 years (24-48 months), are more vulnerable to infection, because children less than 4 years old may contract infections, during intense activities and adventures such as crawling or walking on ground, sand or grasses or children were eating mud/pica and were positive for intestinal parasites [5] indicating soil contamination is one of the common determinants of infection.

Furthermore, the least infected age groups in this study were 6-24 and 49-59 months old children. According to Kazura et al. (1996) cited in [19], most children do not start to walk by the age of 13 months, therefore they might not be strong enough to go out and get contaminated until the age of 2 years, unless it is home based contamination. The prevalence rates of this result was more or less consistent with report of Kazura et al. (1996), however, less prevalence of infection rate among children aged 49-59, which would be probably due to health intervention as well as the development of immunity against intestinal parasites.

Stool examination, also showed infection of protozoan parasites including Giardia lamblia and amoeba species nearly in all age groups probably due to water and food contamination and poor environmental sanitation, [4], showing the wide distribution of intestinal parasites particularly in children.

Much of the infections of the intestinal parasites did not show variation among male and female children. However, the prevalence rate of Trichuris trichiura affected more male children $(6.4 \%)$ than female children $(2.7 \%)$. This prevalence rate of infection, as reported earlier on parasitic infection, culturally is clear that girls do stay at home with their mothers which decrease risk of infection while boy's especially older ones go to field with their fathers, so that their exposure to geohelminths is likely to increase. However, in our case, the children under investigation, were under five years, and have more or less equal exposure to contamination, so the higher prevalence rate of Trichuris trichiura in male children than females needs further investigation.

\section{CONCLUDING REMARKS}

The percentage of children with stool positive for parasites indicate the gross lack of personal hygiene and constant food, water and soil pollution. There is no doubt this resulted in repeated exposure and infection with the resultant high prevalence of intestinal parasites acquired during infancy and their after. Thus, effective plumbing, rather than effective medical treatment is the real line of defense against these versatile pathogens including intestinal parasites [12]. 
This study showed the high prevalence of intestinal parasites in asymptomatic children less than five years, mainly ascaris, amoeba species and trichuris which were dominant parasites. Besides, variations of parasitosis in different study areas of the selected regions were observed, which may be due to the results of different factors including different health intervention strategies such as, regular treatment, deworming, vaccination etc. However, these interventions alone cannot bring a sustainable solution to prevention and control of parasitic infection. Along with deworming, and other health interventions, we need to include Vitamin $A$ and micronutrient supplementation, public mobilization with the special attention to mothers/caretakers, involving awareness creation on infection cycles of parasites, and determinant factors enhancing parasitic transmission including, poor environmental sanitation, personal hygiene, poor water supply, etc. in both urban and rural areas.

\section{ACKNOWLEDGEMENTS}

I would like to thank Dilla University, for facilitating ground to a research work in general, NUFU project in particular for financing the research activity. I am also grateful to Ato Melese Mariyo, for his genuine and collaborative work, Dr Girma Ababi, specialist in human pathology, for his general constructive comments on the vital aspects of the research, and Dr Wondimeneh Bekele, specialist in pediatrics, who prescribed antiparasitic drugs to treat children with intestinal parasitic infection. I also extend my sincere gratitude to Ato Mohammed Aliye a laboratory technologist who assisted me during the diagnosis of intestinal parasites, and all other individuals who contributed their share to the success of this study.

\section{REFERENCES}

[1] Zeibig EA. Clinical parasitology: A practical approach. W.B. Saunders Company, USA 1997; 320.

[2] Adeoye CO, Osyayeni CO, Oteniya O, et al. Epidemiology of intestinal helminhts and Malaria among children below two years in Legos., Nigeria. Pak J Biol Sci 2007; 10(3): 2202-12.

[3] Paniker CKJ. Text book of medical parasitology. Jaypec Brothers. Med Parasitol 2002; 221.

[4] Etim IJ, Akpan PA. A study on the geography as the risk factors for the geohelminthiasis in Calaba, cross river Nigeria. J Parasitol 1999; 20: 91-98.

[5] Muntaz S, Siddiqui H, Ashfag T. Frequency and Risk factors for intestinal parasitic infection in children under five years age at tertiary care hospital in Karach. J Pak Med Assoc 2009; 59: 216-26.

[6] Pellai DR, Kain KC. Intestinal parasites among children. Current treat opt. Infect Dis 2003; 5: 2007-17.
[7] Minenoa T, Avery MA. Giardiasis: Recent progress in chemotherapy and drug development. Curr Pharm 2003; 9: 841-55.

[8] Bethony J, Brooks S, Albomico $\mathrm{M}$, et al. Soil transmitted helminth infection: ascariasis trichuriasis, and hookworm. Lancet 2006; 367: 1521-32.

http://dx.doi.org/10.1016/S0140-6736(06)68653-4

[9] De Silva NR, Brooker S, Hotez PJ, et al. Soil-transmitted Helminth infection: updating the global picture. Trends Parasitol 2003; 19: 547-51. http://dx.doi.org/10.1016/j.pt.2003.10.002

[10] Crompton DW. How much Human helminthiasis is there in the world? J Parasitol 1999; 85: 397-403. http://dx.doi.org/10.2307/3285768

[11] Mehraj V, Hatcher J, Akhater R, et al. Prevalence and factors associated with intestinal parasitic infection among children in an Urban Slum of Karachi. Plos ONE 2008; 3(11): e3680. http://dx.doi.org/10.1371/journal.pone.0003680

[12] Egido JM, De-Dlego JA, Penin P. The prevalence of enteropathy due to strongyloidiasis in puerto, Maldonado (Peruvion, Amazon). Braz J Infect Dis 2001; 5(3): 1413-70. http://dx.doi.org/10.1590/S1413-86702001000300003

[13] Lynne S, Garcia MS, David A, et al. Diagnostic Medical Parasitology, third ed. ASM press, Washington, D.C. 2005; 937.

[14] Connolly KJ, Kvalbvig JD. Infection, nutrition and cognitive performance in children. Parastol Today 1992; 104: 87-200.

[15] Mengistu A, Gebreselassie S, Kassa T. Prevalence of intestinal parasitic infections among urban dwellers in southern Ethiopian. J Health Develop 2007; 21(1): 12-17.

[16] Haile G, Jirra C, Moha T. Intestinal parasitism among, Jiren elementary and junior secondary school students, Southwest Ethiopia. Ethiopian J Health Develop 1994; 8: 37-41.

[17] CSA. The Central Statistics authority: National Statistics, A.A. CSA, the 1994 Population and Housing Census of Ethiopia; Results for Southern Nations 2007.

[18] Arora Bs, Arora DR. Practical Microbiology. BC publishers and Dsitributors. New Delhi 2007; 218.

[19] Airoong BW, Srijan A, Serichantalerg O. et al. Intestinal parasitic infection among preschool children in Sanghlaburi, Thailand. Am J Trop Med Hygiene 2007; 76(2): 345-50.

[20] Haileamlack A. Intestinal parasites in asymptomatic children in Southern Ethiopia. Ethiopian J Health Sci 2005; 5(2): 107105.

[21] Schmist GD. Roberts LS. Foundation of parasitology. Tims Mirror Mosby college publishing, $4^{\text {th }}$ ed st. Louis 1989.

[22] Bemen A, Guyatt H. Reducing intestinal nematode infection. Efficacy of albendazole and Mmbendazole. Parasitol Today 2000; 16: 71-74 http://dx.doi.org/10.1016/S0169-4758(99)01544-6

[23] Allen HE, Crompton DWT, Silva N. New policies for using antihelminthic drugs in high risk groups. Trends Parasitol 2002; 18: 381-82.

http://dx.doi.org/10.1016/S1471-4922(02)02386-3

[24] Glickman LT, Camera AO, Glickman NW, et al. Nematode intestinal parasites of children in rural Guinea in Africa: $A$ prevalence and relationship to geophagia. Int $\mathrm{J}$ Epidemiol 1999; 28: 169-74. http://dx.doi.org/10.1093/ije/28.1.169

[25] Adnan I, Hindi Al, Kichaoi El. Occurrence of Gastrointestinal Parasites Among Pre-School Children, Gaza, Palestine. The Islamic University Journal 2008; 16(1)L 125-130. ISSN 17266807.

[26] Asaolu SO, Ofoezie IE, Odumuyiwa PA, Sowemimo OA, Ogunniyi TAB. Effects of water supply and Sanitation on the prevalence of Ascaris lumbricoides on preschool age 
children Ajebanddele and Ifewara, Oscan State Nigeria.

Trans Royal Soc Trop Med Hygiene 2000; 96: 600-604.

http://dx.doi.org/10.1016/S0035-9203(02)90323-8
[27] Costa, Macedo LM, Rey L. Maternal and Child intestinal parasites and Breast Feeding.Revista $\mathrm{Da}$ Sociedade Brasileiera De Medicina. Tropical 2000; 33: 371-75.

Received on 23-05-2013

Accepted on 14-08-2013

Published on 31-08-2013

http://dx.doi.org/10.6000/1929-4247.2013.02.03.3

(c) 2013 Abayneh Unasho; Licensee Lifescience Global.

This is an open access article licensed under the terms of the Creative Commons Attribution Non-Commercial License (http://creativecommons.org/licenses/by-nc/3.0/) which permits unrestricted, non-commercial use, distribution and reproduction in any medium, provided the work is properly cited. 